\title{
Ultrasonography: Sports Injuries
}

\author{
Gina M. Allen and Jon A. Jacobson
}

\section{Learning Objectives}

- To understand the value of ultrasound in the examination of sports injuries.

- To be familiar with common sport-related disease of the upper extremity.

- To be familiar with common sport-related disease of the lower extremity.

\subsection{Upper Extremity}

\subsubsection{Introduction}

Ultrasound is an effective imaging method for evaluation of upper extremity sports injuries. For evaluation of the shoulder, ultrasound is ideal in assessment of the rotator cuff, the biceps brachii tendon and the subacromial-subdeltoid bursa. Evaluation of the cartilaginous structures of the shoulder is significantly limited, and therefore MRI and preferably MR arthrography are considered in this scenario. An algorithm based on patient age is often used, where patients over the age of 40 years often are evaluated with ultrasound and patients under 40 years are evaluated with MRI or MR arthrography. This algorithm is used as patients under the age of 40 years will often have articular-sided partialthickness rotator cuff tears and concomitant labral pathology, both of which are ideally seen with MRI [1]. Beyond the shoulder, ultrasound is most accurate when the indication for imaging is targeted and the structure imaged is superficial. Last, ultrasound complements MRI given its ability to

\section{G. M. Allen}

St Luke's Radiology Oxford Ltd, Oxford, Oxfordshire, UK

e-mail: gina@slro.co.uk

\section{J. A. Jacobson $(\varangle)$}

Radiology, University of Michigan, Ann Arbor, MI, USA

e-mail: jjacobsn@med.umich.edu dynamically assess pathology of the upper extremity. Given the superficial location of soft tissue abnormalities, a linear transducer of greater than $12 \mathrm{MHz}$ is preferred, and a small footprint probe is used for the most distal aspects of the upper extremity.

\subsubsection{Shoulder}

The rotator cuff is the most commonly imaged tendon group using ultrasound, where its accuracy in the diagnosis of cuff pathology is equal to MRI. Unlike the distal aspects of the upper extremity, a protocol-based evaluation with ultrasound is recommended as symptoms do not always directly correlate with pathology, and symptoms may also be multifactorial in aetiology [2]. Each individual rotator cuff tendon (supraspinatus, infraspinatus, subscapularis, teres minor) is imaged in short and long axis. Given the curvature of the humeral head and the overlying supraspinatus, care must be taken not to misinterpret artefactual hypoechogenicity from anisotropy as tendon abnormality. Pathology of the rotator cuff, similar to other tendons, include tendinosis and tendon tear. The term tendinosis is used rather than tendinitis as inflammation diminishes after the first week after a tendon injury [3]. Tendinosis refers to mucoid degeneration and chondroid metaplasia of the involved tendon [4, 5]. At ultrasound, tendinosis will appear as abnormal hypoechogenicity with possible increased in tendon thickness [6]. Tendon tear will appear as a well-defined hypoechoic or anechoic defect in the normal hyperechoic fibrillar tendon architecture. Such tendon tears may be partial-thickness and only involve the articular surface, bursal surface or may be intrasubstance (or interstitial) not contacting either the articular (Fig. 16.1) or bursal surface of the tendon, although isolated greater tuberosity extension is common. A full-thickness tear will extend from the articular to bursal surface of the tendon. Of note, most supraspinatus tendon tears extend to the greater tuberosity footprint, which creates the cortical irregularity as a 


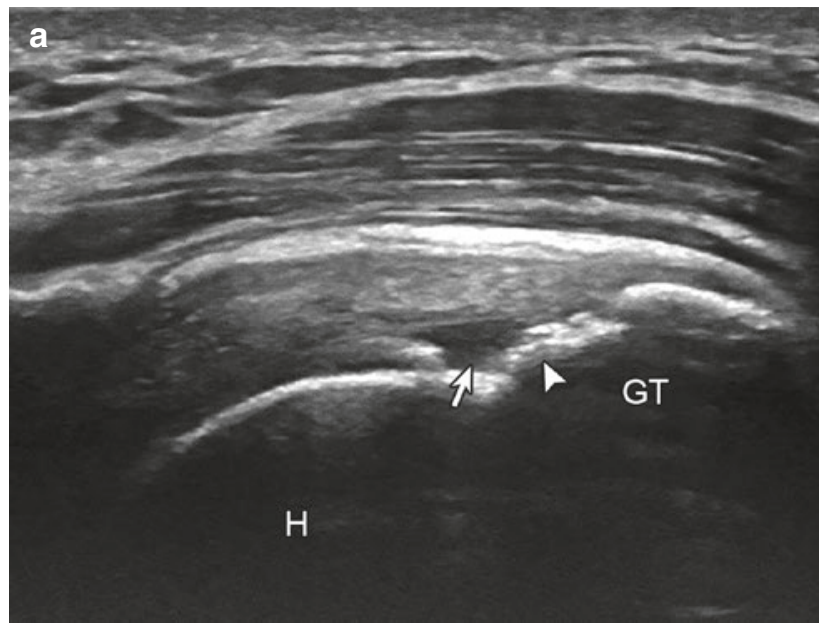

Fig. 16.1 Supraspinatus tear: articular side partial-thickness. Ultrasound images long axis (a) and short axis (b) to supraspinatus tendon show hypoechoic tendon tear (arrows) extending to the articular surface of the

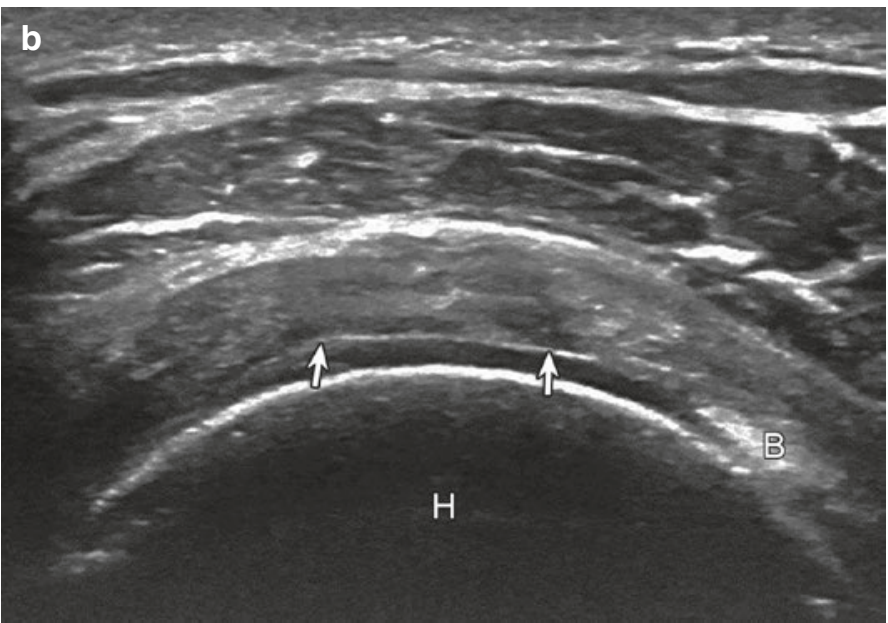

humeral head $(\mathrm{H})$. Note cortical irregularity (arrowhead) of greater tuberosity (GT). B Biceps brachii long head tendon in rotator interval

and blends into the supraspinatus tendon when imaging proximally. Ultrasound may also be used to dynamically assess for biceps brachii tendon subluxation and dislocation and guide percutaneous tendon sheath injection [12].

Another common structure that is abnormal with overuse injuries is the subacromial-subdeltoid bursa. This composite bursa is quite extensive located deep to the deltoid and covering portions of the supraspinatus, infraspinatus, subscapularis, biceps brachii long head and proximal humerus. Distention of the bursa may range from anechoic fluid to hypoechoic or hyperechoic synovial hypertrophy [13]. To diagnose subacromial impingement with ultrasound, the arm is abducted, and ultrasound will reveal gradual distention of the subacromial-subdeltoid bursa at the edge of the acromion; however, this finding may be found in asymptomatic individuals, and clinical correlation is required [14]. Ultrasound may also be used to guide percutaneous bursal injection.

\section{Key Points}

- Cortical irregularity of the greater tuberosity is a helpful secondary sign of a supraspinatus tear.

- Fluid surrounding the biceps brachii long head tendon is most commonly due to a communicating glenohumeral joint effusion.

- Subacromial-subdeltoid bursal distention can range from anechoic fluid to hyperechoic synovial hypertrophy. 

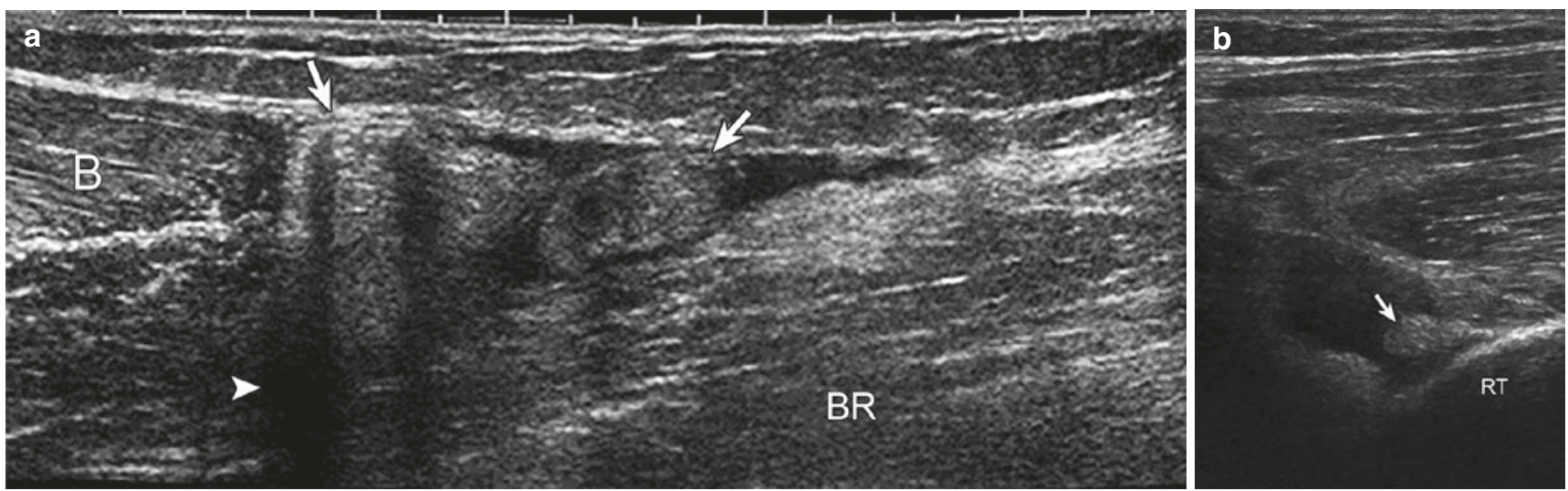

Fig. 16.2 Biceps brachii: full-thickness tear. Ultrasound images show (a) proximal and (b) distal stumps of the torn and retracted biceps brachii (arrows). Note refractions shadowing (arrowhead) deep to recoiled

\subsubsection{Elbow}

The distal biceps brachii tendon may show findings of tendinosis (hypoechoic enlargement), partial-thickness tear (anechoic clefts) and full-thickness tear (complete tendon discontinuity) (Fig. 16.2) associated with sports injuries [15]. Ultrasound imaging of the distal biceps brachii tendon is often difficult given the oblique course of the distal tendon and resulting anisotropy. Imaging the biceps tendon from a medial or pronator window approach, with possible elbow flexion, is often helpful [16]. Partial-thickness biceps tears may involve one of the two heads, commonly the more superficial short head, which can create refraction shadowing artefact possibly obscuring the deeper long head tendon. In differentiating partial-thickness from a full-thickness tendon tear, the use of dynamic evaluation is helpful, either imaging from a medial or lateral approach [17]. With supination and pronation, lack of tendon movement to the same degree as radial tuberosity rotation is indirect evidence of a full-thickness tear. Often fullthickness distal biceps brachii tendon tears will be associated with significant tendon retraction.

Distal triceps brachii tendon tear are also effectively assessed with ultrasound. Partial-thickness tears often involve the superficial combined long and lateral heads, associated with an avulsed enthesophyte bone fragment (Fig. 16.3) [18]. The deeper medial head is often intact but may be erroneously interpreted as torn given that the medial head tendon is very short. Tendinosis may uncommonly involve the distal triceps brachii tendon, as well as distention of the overlying olecranon bursa.

Epicondylitis may also be diagnosed with ultrasound. With lateral (tennis elbow) more common than medial (golf- proximal stump in (a). $B$ biceps brachii muscle, $B R$ brachialis muscle, $R T$ radial tuberosity

er's elbow), the term "epicondylitis" is a misnomer in that it is not a primary epicondyle problem and is not actively inflamed [19]. The underlying pathology, similar to other tendons, represents tendinosis, interstitial tear or uncommonly full-thickness tear (Fig. 16.4). The presence of hyperemia on colour Doppler imaging correlates with symptoms and represents neovascularity rather than an indirect sign of inflammation.

The ulnar collateral ligament is evaluated dynamically with ultrasound and complements MR arthrography where the accuracy in diagnosis of tear is highest when both imaging methods are used [20]. With the elbow flexed at least $30^{\circ}$, valgus stress is placed across the elbow. Asymmetric widening of the medial joint space between the humerus and ulna with valgus stress can indicate ligament tear [20]. The ulnar nerve can also be imaged by dynamic ultrasound to assess for injury or subluxation.

\section{Key Points}

- Evaluating the biceps brachii tendon medially and laterally complements anterior evaluation.

- Triceps brachii partial tears most commonly involve the superficial layer with avulsion of an enthesophyte.

- Hyperemia of the common extensor tendon represents neovascularity and not inflammation.

- Dynamic evaluation of the ulnar collateral ligament with valgus stress assesses joint space gapping to indicate tear. 
Fig. 16.3 Triceps brachii: partial-thickness tear.

Ultrasound image long axis to triceps brachii $(\mathrm{T})$ shows retracted tear of superficial combined lateral and long head tendons (between arrows) with hyperechoic and shadowing enthesophyte avulsion fragment (curved arrow). Note intact deep medial head of triceps brachii (arrowheads). $O$ olecranon process
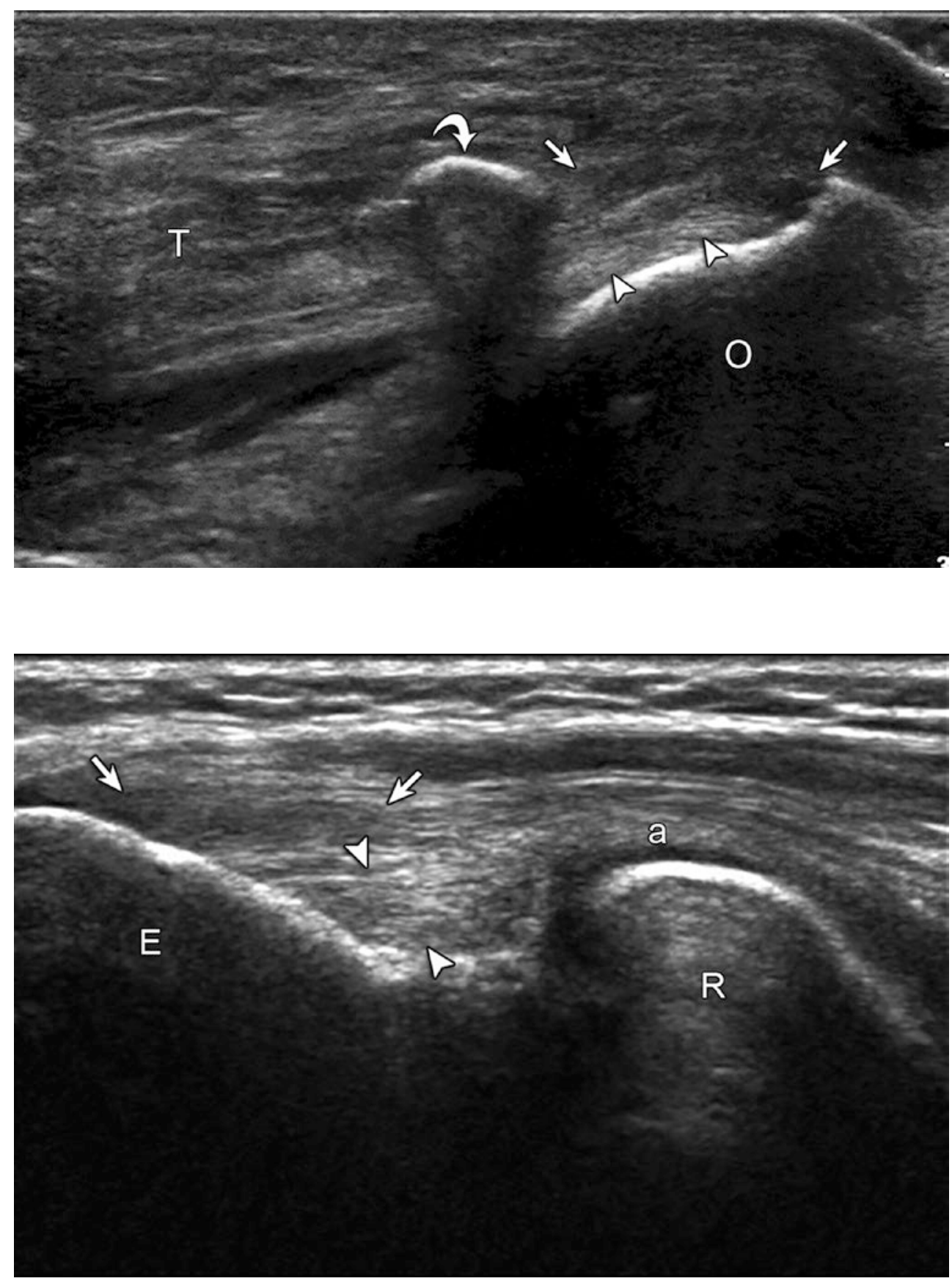

Fig. 16.4 Common extensor tendon abnormality (lateral epicondylitis). Ultrasound image long axis to common extensor tendon shows hypoechoic tendinosis (arrows). Note radial collateral ligament proper (arrowheads). $E$ lateral epicondyle, $R$ radial head, $a$ annular ligament

\subsubsection{Wrist and Hand}

Sports injuries of the hand and wrist are often ligamentous or related to the triangular fibrocartilage complex, which are best evaluated with MR or preferably MR arthrography; however, ultrasound can be used to evaluate focal tendon abnormalities. For example, intersection syndrome will appear as asymmetric hypoechoic swelling, oedema and possible hyperemia where the first extensor wrist compartment muscles (extensor pollicis longus and abductor pollicis brevis) cross over the second extensor wrist compartment (extensor carpi radialis longus and brevis) [21]. This can be very subtle and a very light pressure on the transducer is needed to see fluid in these cases. Full-thickness tendon tears are often associated with tendon retraction. Related to the extensor tendons, sagittal band injury at the level of the metacarpophalangeal joints is diagnosed when abnormal hypoechogenicity is seen with asymmetric location of the extensor tendon, best seen dynamically with flexion at the metacarpophalangeal joints, termed Boxer's knuckle [22]. Related to the flexor tendons of the fingers, ultrasound is effective in evaluation of the pulleys of the digits. Non- 
visualisation of a pulley can indicate injury; however, the finding of tendon bowstringing is an important indirect sign of pulley injury, which appears as an abnormal position of the flexor tendon not approximated to the phalanx (Fig. 16.5). Bowstringing is evaluated dynamically with active finger flexion against resistance where a distance between the flexor tendon and phalanx greater than $1 \mathrm{~mm}$ indicates pulley injury; a distance greater than $3 \mathrm{~mm}$ indicates a complete A2 pulley tear; and a distance of $5 \mathrm{~mm}$ indicates a combined complete tears of A2 and A4 pulleys [23].

One ligament that is ideally assessed with ultrasound is the ulnar collateral ligament of the thumb [24]. Injury to this ligament, termed skier's or gamekeeper's thumb, can range from sprain (hypoechoic swelling), partial tear (partial anechoic defect) and complete tear (discontinuous ligament), with the latter either being non-displaced or displaced [25]. A displaced ulnar collateral ligament tear with an interposed adductor aponeurosis is termed a Stener lesion. Ultrasound is able to diagnose a Stener lesion with $100 \%$ accuracy [24]. Key to evaluation is correct placement of the transducer in the coronal plane relative to the thumb with visualisation of the characteristic bone contours at the expected attachments of the ulnar collateral ligament. The adductor aponeurosis is identified as a thin hypoechoic structure that normally overlies the intact ulnar collateral ligament, where flexion and extension at the interphalangeal joint cause isolated movement of the aponeurosis, which aides in its identification. The distal aspect of the displaced ulnar collateral ligament is identified as a hypoechoic round abnormality proximal to the metacarpal joint (Fig. 16.6), with a possible hyperechoic and shadowing avulsion bone fragment. The end of the torn ligament may be seen superficial to the adductor aponeurosis or may be seen along the distal metacarpal shaft with the ligament coursing proximal.
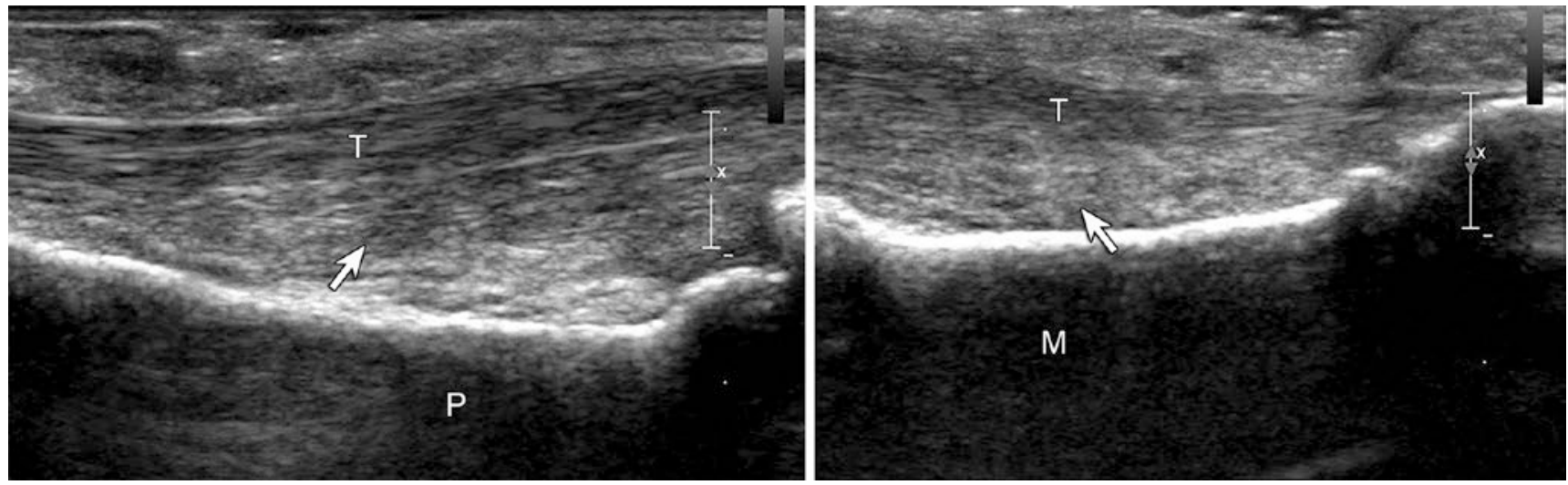

Fig. 16.5 Pulley injury. Ultrasound image long axis to the flexor tendons $(\mathrm{T})$ of the finger shows abnormal volar displacement or bowstringing of the tendons (arrows) opposite the proximal (P) and middle (M) phalanges indicating A2 and A4 pulley tears, respectively

Fig. 16.6 Ulnar collateral ligament tear of the thumb (skier's thumb). Ultrasound image long axis to the ulnar collateral ligament of the thumb shows torn and proximally displaced ligament (arrow) with interposed, hypoechoic and thickened adductor aponeurosis (arrowheads). $M C$ metacarpal, $P$ proximal phalanx

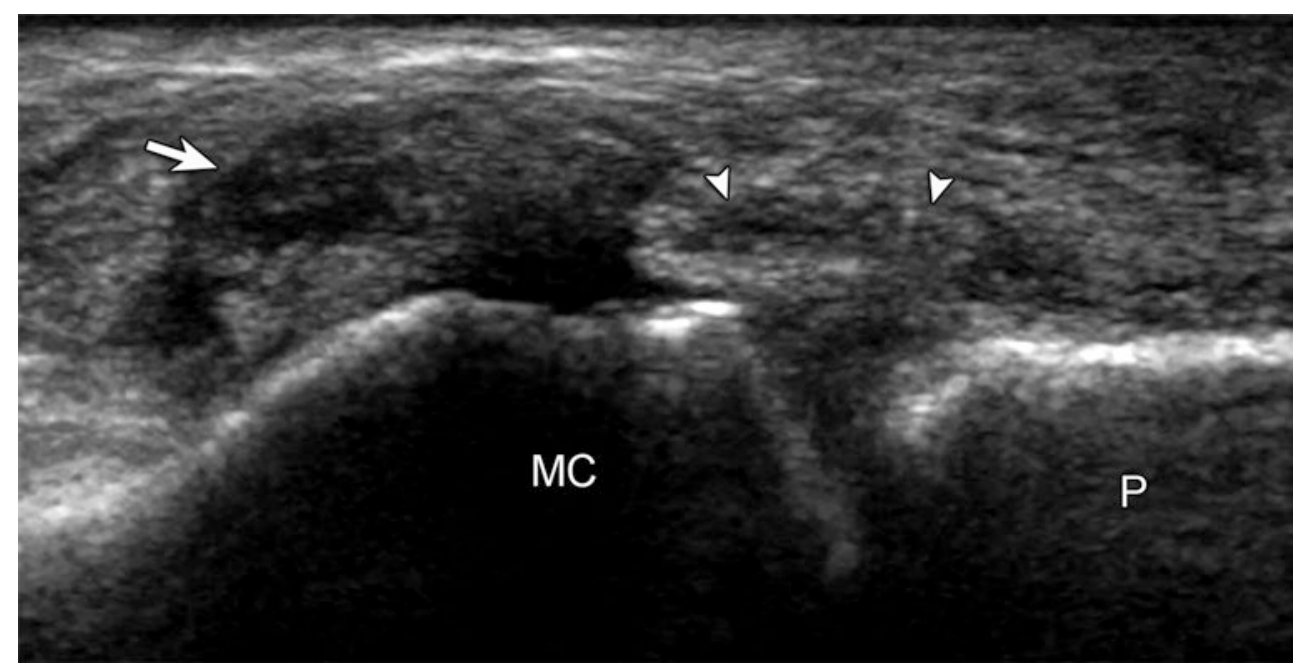




\section{Key Points}

- Tendon retraction indicates full-thickness tear.

- Flexor tendon bowstringing indicates pulley injury.

- Ultrasound can diagnose a Stener lesion with very high accuracy.

\subsection{Lower Extremity}

\subsubsection{Introduction}

For athletic injuries, diagnostic ultrasound is used daily as a "stethoscope" to confirm injury and guide treatment. It is not only performed by radiologists but also by sports physicians, physiotherapists and orthopaedic surgeons, to name a few [26].

Ultrasound examination is very important in the assessment of lower limb injuries because of its dynamic capabilities and excellent line pair resolution. Vascularity can be demonstrated within a structure without the need for intravenous contrast agent by pressing a button. Recently microvascular imaging allows us to observe subtle vascularity. Vascular supply is important in determining the nature and the time course of an injury. If increased, it indicates that an injury is in the acute or subacute phases, while its absence means that the injury is old. It is also be used to date tendinopathy. There may be some correlation with a painful tendon, but it is particularly useful in determining resolution after treatment.

In our practice diagnostic ultrasound is the first-line investigation for tendon, ligament and nerve-related disorders. It is also useful in detecting effusions and synovitis within joints. Ultrasound can reliably demonstrate small avulsion fractures at the site of ligamentous attachment which are difficult to see on conventional radiography and MRI. Dynamic stress across a ligament or tendon in the con- text of injury can determine and emphasise the degree of separation of the injured fibres. With high-resolution ultrasound probes, normal or diseased nerves can be directly seen. When metal work is present ultrasound will demonstrate structures that would be obscured by artefact on other imaging. The presence of intermittent impingement of a tendon, ligament or nerve can be assessed dynamically and precisely. Ultrasound examination is often the only imaging that will demonstrate this important phenomenon.

\subsubsection{Pelvis}

\subsubsection{Groin Pain}

To examine the groin, you will need a probe that has a range of frequencies demonstrating superficial to deep structures.

Ultrasound is a very useful technique in the diagnosis of groin pain as it can cover many areas that can cause pain [27, 28]. Dynamic assessment for hernias is important (Fig. 16.7). In a study of groin pain, $89 \%$ of symptomatic athletes had inguinal hernias compared to $12 \%$ asymptomatic controls. Most of the athletes returned to normal sporting activity after surgery [29].

With diagnostic ultrasound, you can assess the exact site of the pain as demonstrated by the patient and examine the nearby joint, tendon insertions and muscles.

\subsubsection{Hip}

Ultrasound examination of the hip needs a probe covering the $12-8 \mathrm{MHz}$ range due to the joint's depth. Imaging should start obliquely along the line of the femoral neck.

Diagnostic ultrasound can detect an effusion, synovitis within the hip joint and sometimes labral tears especially if they are associated with paralabral cysts. The technique has greater sensitivity for cysts than MRI but less sensitivity for labral tears than MRI arthrography. The presence of synovi-
Fig. 16.7 Direct inguinal hernia. Soccer player with groin pain but no clinical evidence of a hernia. The hernia is best appreciated on the dynamic assessment. You can see a loop of bowel moving forward on Valsalva. Static view is provided in this article

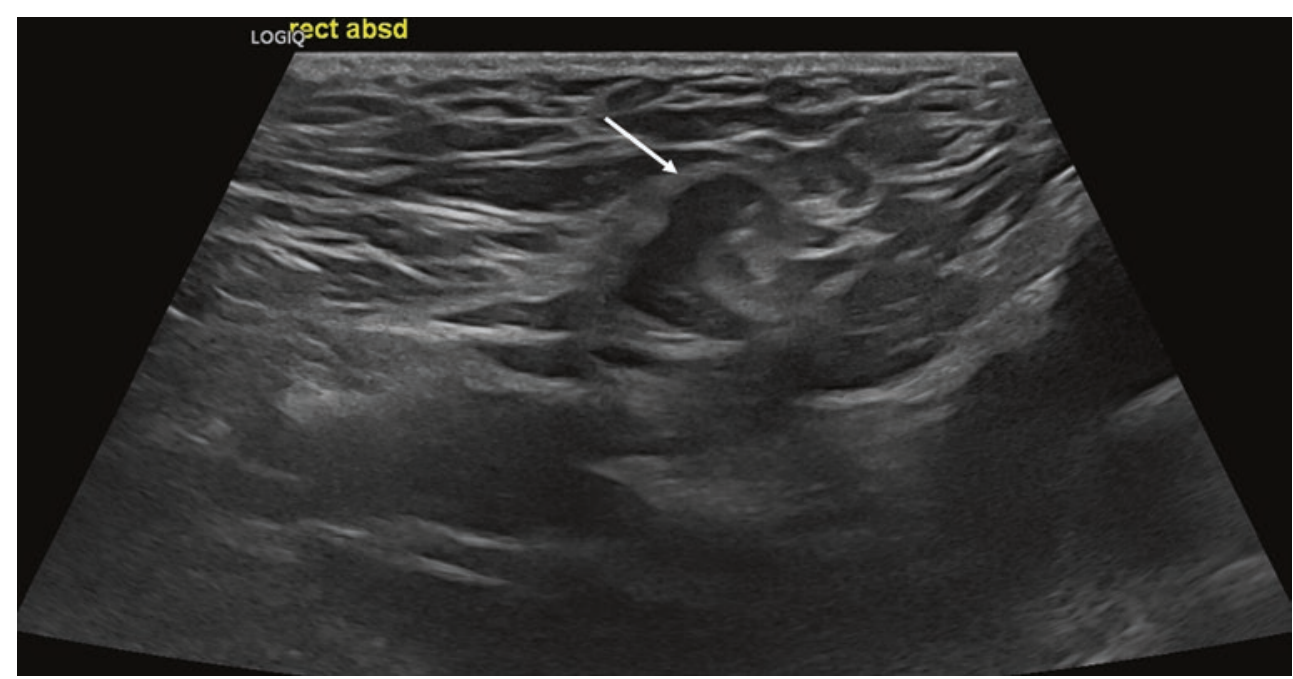


tis with its higher echogenicity, neovascularity and frondlike appearance against the anechoic fluid of an effusion is seen with standard ultrasound. MRI would require intravenous contrast agent enhancement and a longer examination to achieve similar results. A substantial benefit of diagnostic ultrasound is that it clearly differentiates cystic versus solid mass lesions. This is often difficult using MRI.

In younger athletes the most injured areas are the joint and the labrum. These are best seen with MR arthrography, but ultrasound can be used to guide the arthrography injection and guide pain-relieving injections such as steroid and sodium hyaluronic acid in the treatment of conditions that do not need surgery.

\section{Key Points}

- Groin pain can be due to hernias which can be reliably identified by dynamic ultrasound examination.

- To detect a hip effusion, the probe is best placed obliquely along the line of the femoral neck.

\subsubsection{Insertional Tendinosis (Traction Enthesopathy)}

Diagnostic ultrasound is useful in the athlete in detecting tendinopathies around the hip.
Age determines the weakest area of the tendon. Before apophyseal closure, the apophyseal attachment is the weakest, and avulsion injuries usually pull off a fragment of bone. These fragments may be very difficult to identify using MRI but are obvious when using ultrasound as they cast an acoustic shadow and a sharp margin [30]. In adults with repetitive stress, the tendon insertion may be injured. The appearances on ultrasound of an abnormal tendon are identical to that described in the upper limb, with reduction in echogenicity, often neovascularisation and irregularity of the bone cortex due to enthesopathy.

In the adolescent, the pelvis is a common area for apophyseal injuries. Without the need for radiation, comparing both sides, the area of tendon insertion can be imaged by diagnostic ultrasound. The injuries occur before the age of 20 . The most common apophyseal injuries occur at the insertion of the hamstrings, rectus femoris, sartorius and iliopsoas at the ischial tuberosity (54\%), anterior inferior iliac spine $(22 \%)$, anterior superior iliac spine (19\%) and the lesser tuberosity of the femur, respectively. Less common sites are the adductor tubercle and the iliac crest [31].

In adult athletes the hamstring insertion is a common site of injury. This can be seen in runners, soccer players and cross-country skiers. Rectus femoris injuries are also seen (Fig. 16.8). Soccer players also acquire adductor insertional injuries and injuries at the insertion of the rectus abdominis muscle.

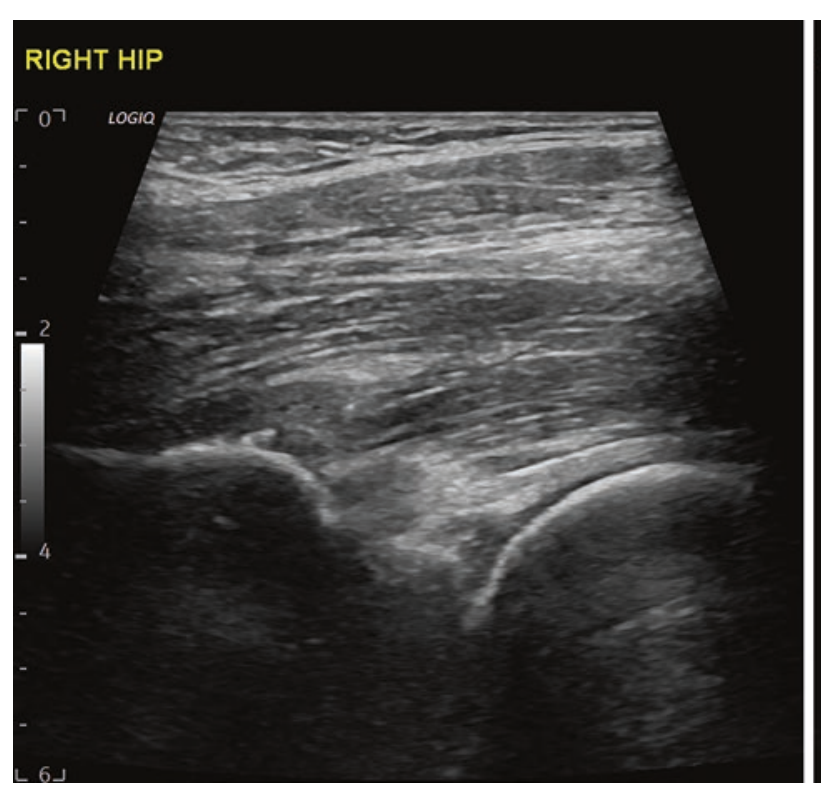

Fig. 16.8 Rectus femoris insertional injury. Horse rider. Left anterior groin pain after gym session 3 weeks before. Clinically thought to be a labral tear. Note the calcification in the insertion of the direct tendon as

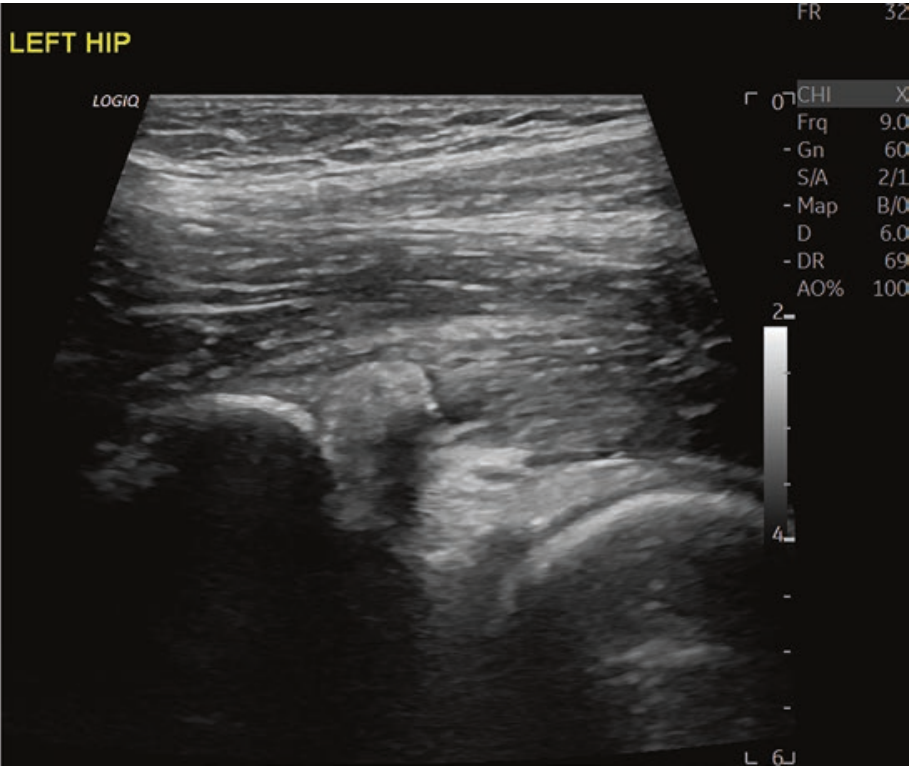

it joins the anterior inferior Iliac spine compared to the asymptomatic normal right side. Side-by-side comparison is very useful in these cases 


\section{Key Points}

- Apophyseal injuries in the adolescent can be detected more accurately by ultrasound than by radiographs or MRI by looking for detached fragments of bone that cause acoustic shadowing.

- Insertional tendinosis or enthesopathy shows reduction of the tendon echogenicity, neovascularity and irregularity of the bone cortex at the insertion.

\subsubsection{Knee}

Most knee injuries are best assessed by MRI to determine both bony and ligamentous injury; however, diagnostic ultrasound is a very useful technique, if there is an area of pinpoint pain or swelling. It can detect effusions and synovitis within the joint and is useful in the assessment and treatment of patellar and quadriceps tendinosis. Collateral ligament injuries and other tendinosis can also be accurately detected and assessed dynamically by ultrasound examination.

The proximal patella tendon is most affected by traction tendinosis. At the insertion into the patella, it becomes thickened and lower in echogenicity and contains neovascularisation (Fig. 16.9). In young athletes, there is also the possibility of an apophyseal injury of both the inferior pole of the patella in Sinding-Larsen syndrome and the tibial tuberosity in Osgood-Schlatter's disease. In its early appearance, these disorders may only show fluid surrounding the tendon with-
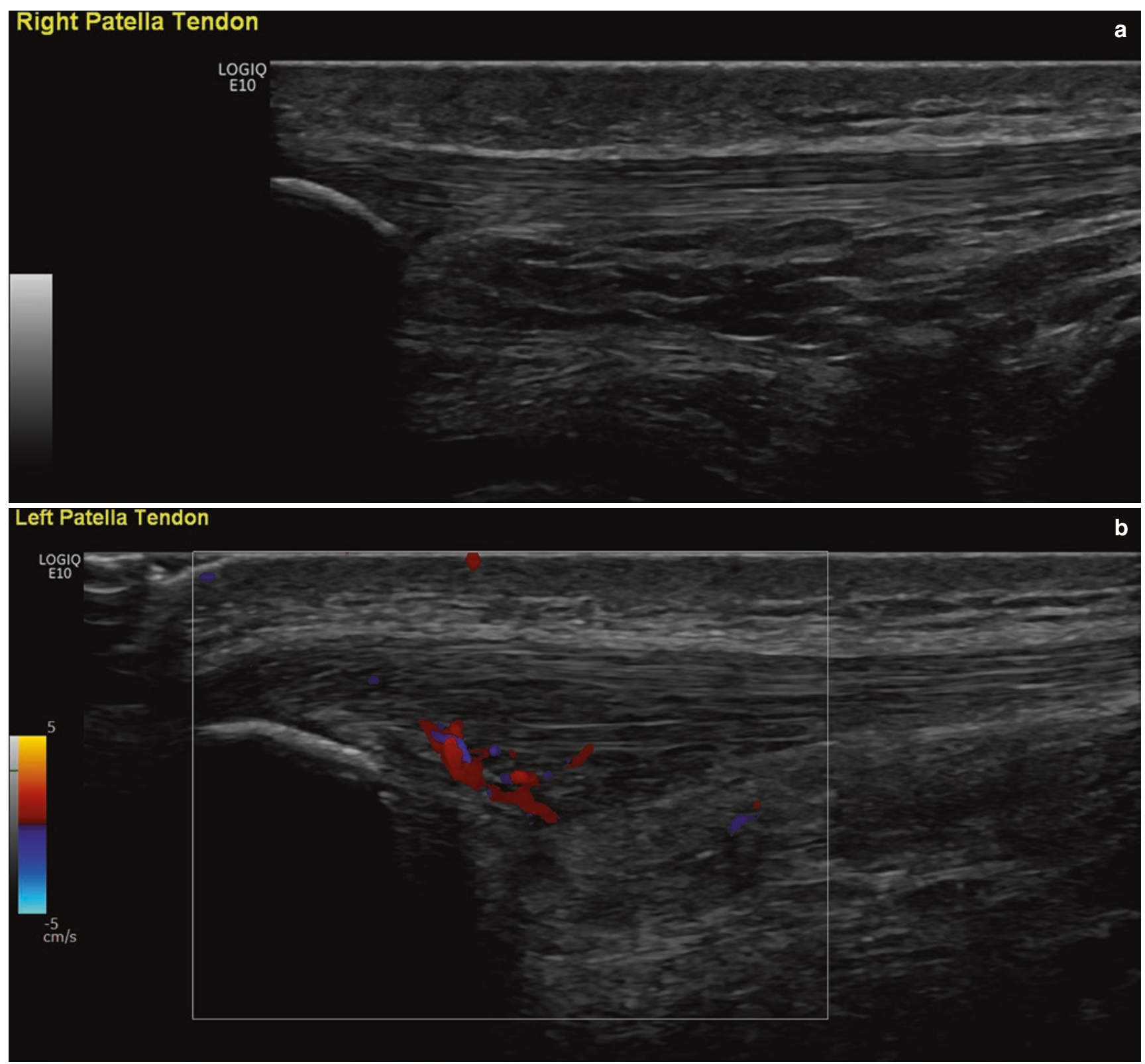

Fig. 16.9 A 22-year-old ballet dancer. (a) Normal right patellar tendon. (b) Insertional patellar tendinosis. Note the thickened proximal tendon with reduced echogenicity and neovascularisation 
out the bony fragmentation as seen in more established cases. These disorders are a traction apophysitis for which offloading is the primary treatment.

Rupture of the patella tendon or quadriceps tendon may occur in the older age group of athletes and can be seen by ultrasound. Here there is a discontinuity of the tendons, and dynamic assessment allows the differentiation of partial- and full-thickness tears. In this last role, diagnostic ultrasound is a much more accurate technique than MRI whether severity and extent of the injuries are difficult to judge.

\section{Key Points}

- Knee effusions are best seen in the suprapatellar region using ultrasound.

- Collateral ligament injuries are easily and accurately assessed by ultrasound, but the other internal knee injuries can only be fully appreciated by MRI.

- Proximal patellar tendinosis is identified by thickening of the tendon with reduced echogenicity and neovascularisation.

\subsubsection{Ankle}

Perhaps the most important area in sports imaging is the ankle. It is important to use a large amount of coupling gel and light touch around this area as pressure over the bones of the ankle can be very painful and you can compress fluid around joints and tendons.

The Achilles tendon is commonly affected in athletes, especially runners. It is best seen by lying the patient prone with the foot dangling off the end of the couch so that movement of the foot can be performed. An $18 \mathrm{MHz}$ probe is the most useful with a larger footplate. Midsubstance tendinosis and insertional tendinosis can be assessed in detail using diagnostic ultrasound. In midsubstance tendinosis, there is a fusiform swelling of the tendon with reduction in echogenicity and neovascularisation. In insertional tendinosis, there is thickening of the tendon, reduction in echogenicity, neovascularisation and often an enthesopathy involving the calcaneal insertion (Fig. 16.10). The presence of a plantaris tendon can also easily be identified. This can be involved in Achilles tendinosis as well or have an isolated tendinosis of its own. The plantaris tendon is important as it may be the
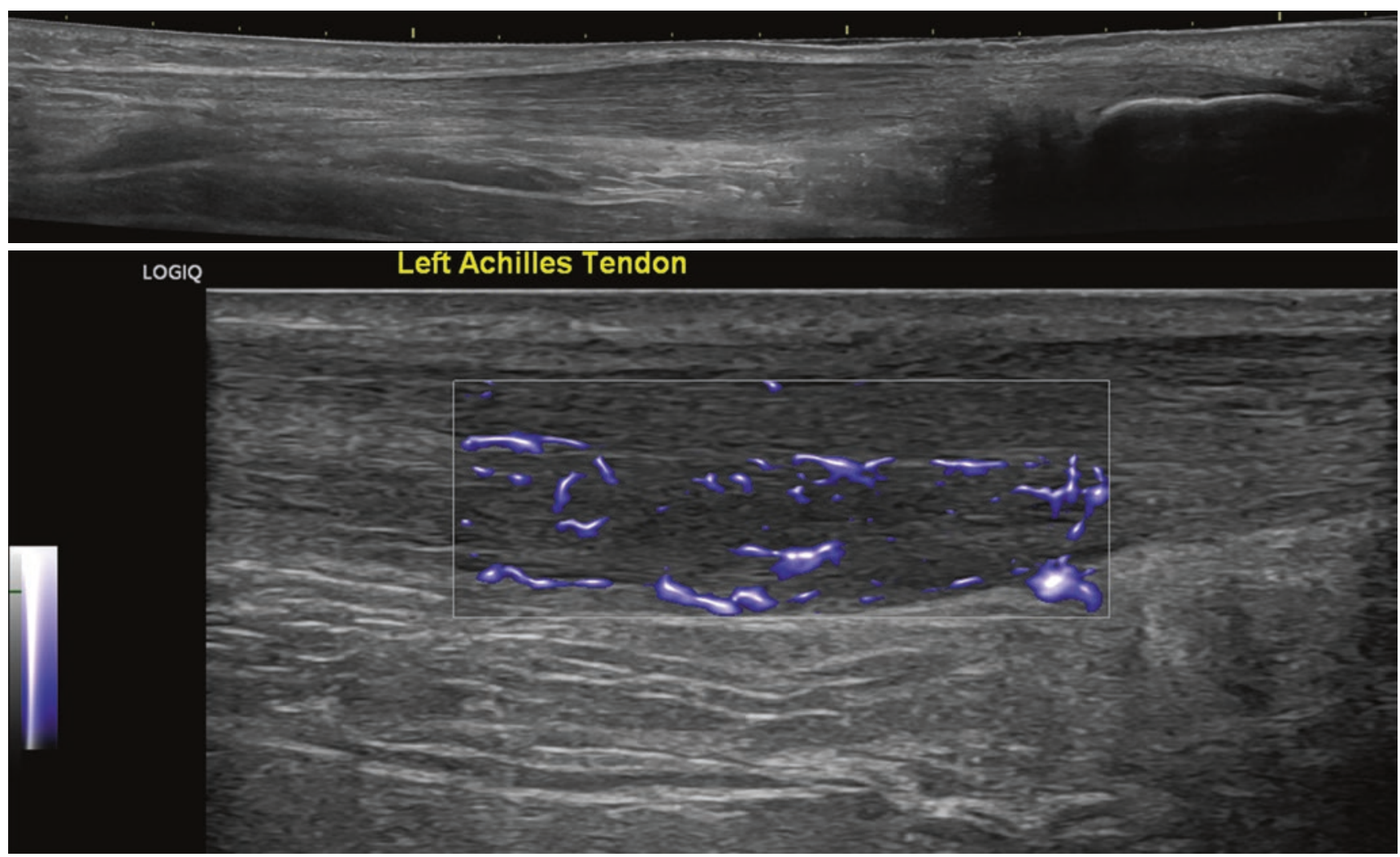

Fig. 16.10 Marathon Runner with Achilles tendinosis. Fusiform swelling of the Achilles tendon with reduction in echogenicity on this extended field of view US image and neovascularity 
reason the patient with Achilles tendinosis is not responding to physiotherapy. Sometimes surgical excision can aid recovery in these cases.

Achilles rupture can occur in athletes. A complete rupture can be identified on diagnostic ultrasound by discordant movement at the site of injury when the tendon ends move in different directions producing a gap in the tendon that increases with dorsiflexion. Ultrasound can precisely locate the area of rupture which allows for measurements to be made and allows the possibility of small incisions to repair the tendon surgically. In the acute injury, it is fortunate that the only movement required is a very minor movement of the foot; if the examination is performed gently and carefully, it should not cause pain even on the day of the injury. The presence of an intact plantaris tendon spanning the Achilles tendon can falsely reassure the clinician that the Achilles tendon is intact as compression of the calf muscles will still cause movement of the foot even though the Achilles tendon itself is fully separated.

Ligamentous rupture is the most common abnormality in athletes. Ankle sprains commonly cause injury to the anterior talofibular ligament in $86 \%$. This can either be a sprain to the ligament or a full rupture. The other lateral ligaments can also be assessed by ultrasound including the anterior tibiofibular ligament which can be injured in association with the anterior talofibular ligament or on its own. In isolation this injury often occurs when an athlete wears high boots such as ski boots or large walking boots. Injury to the calcaneofibular ligament occurs in approximately $30 \%$ of ankle sprains and is a much more significant injury with relatively poor outcome (Fig. 16.11). The posterior tibiofibular and talofibular ligament can also be injured and assessed by ultrasound. Deltoid ligament injury is also common (in 50\% of lateral ligament injuries) [32]. Dynamic assessment of all the ankle ligaments is possible with ultrasound including the posterior ligaments best seen using a small footprint. High-frequency probe with dynamic assessment is especially useful in assessing a syndesmotic injury to the distal tibiofibular joint. On moving the foot in dorsiflexion and plantar flexion, the tibia and fibula should remain at an equal distance apart and in the same location. If there is any dynamic separation of the bones, then this is the diagnosis. This is often missed on any other imaging because you cannot dynamically stress this area on MRI or CT unless you have the facility to perform standing MRI or CT for comparison with supine examination!

Damage to the peroneal retinacula can also occur. The retinacula can become thickened in a chronic injury (Fig. 16.12). If the superior retinaculum is ruptured, this may lead to sublux-

\section{Left Anterior Talofibular Ligament}

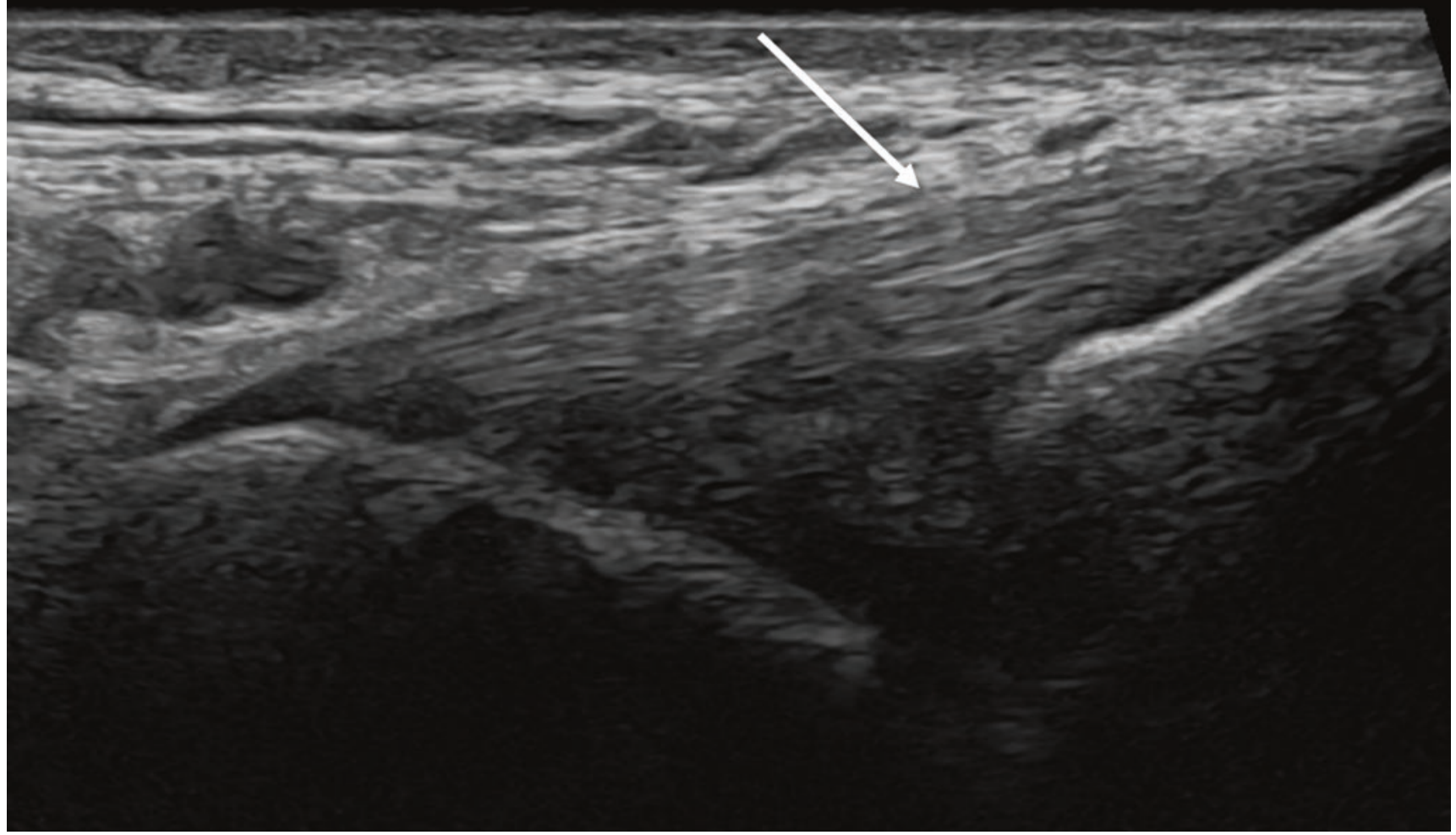

Fig. 16.11 Ruptured anterior talofibular ligament. A 19-year-old soccer player. (a) Normal left anterior talofibular ligament. (b) Torn right anterior talofibular ligament. (c) Injured right calcaneofibular ligament. (d) Right ankle effusion 


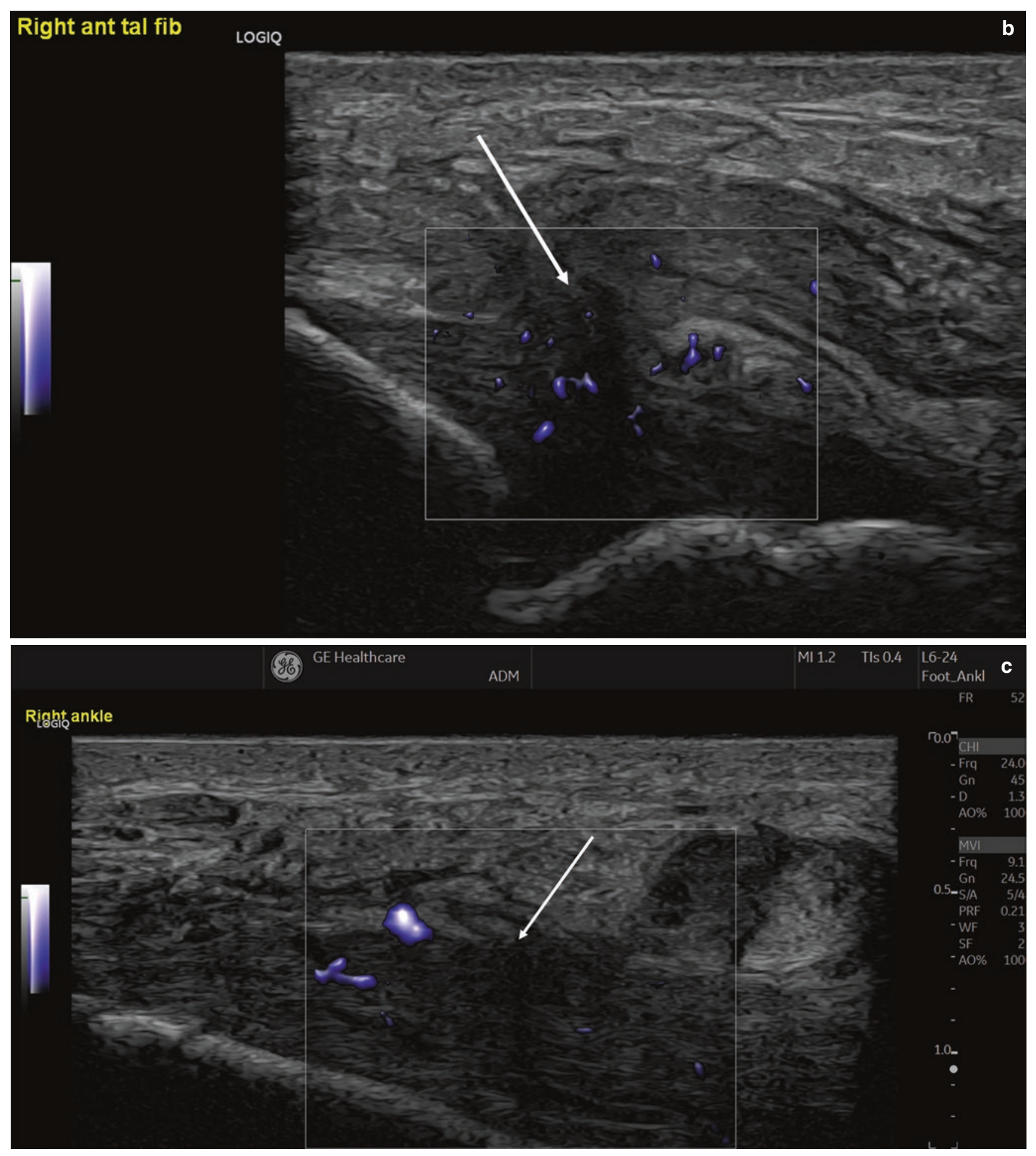

Fig. 16.11 (continued) 


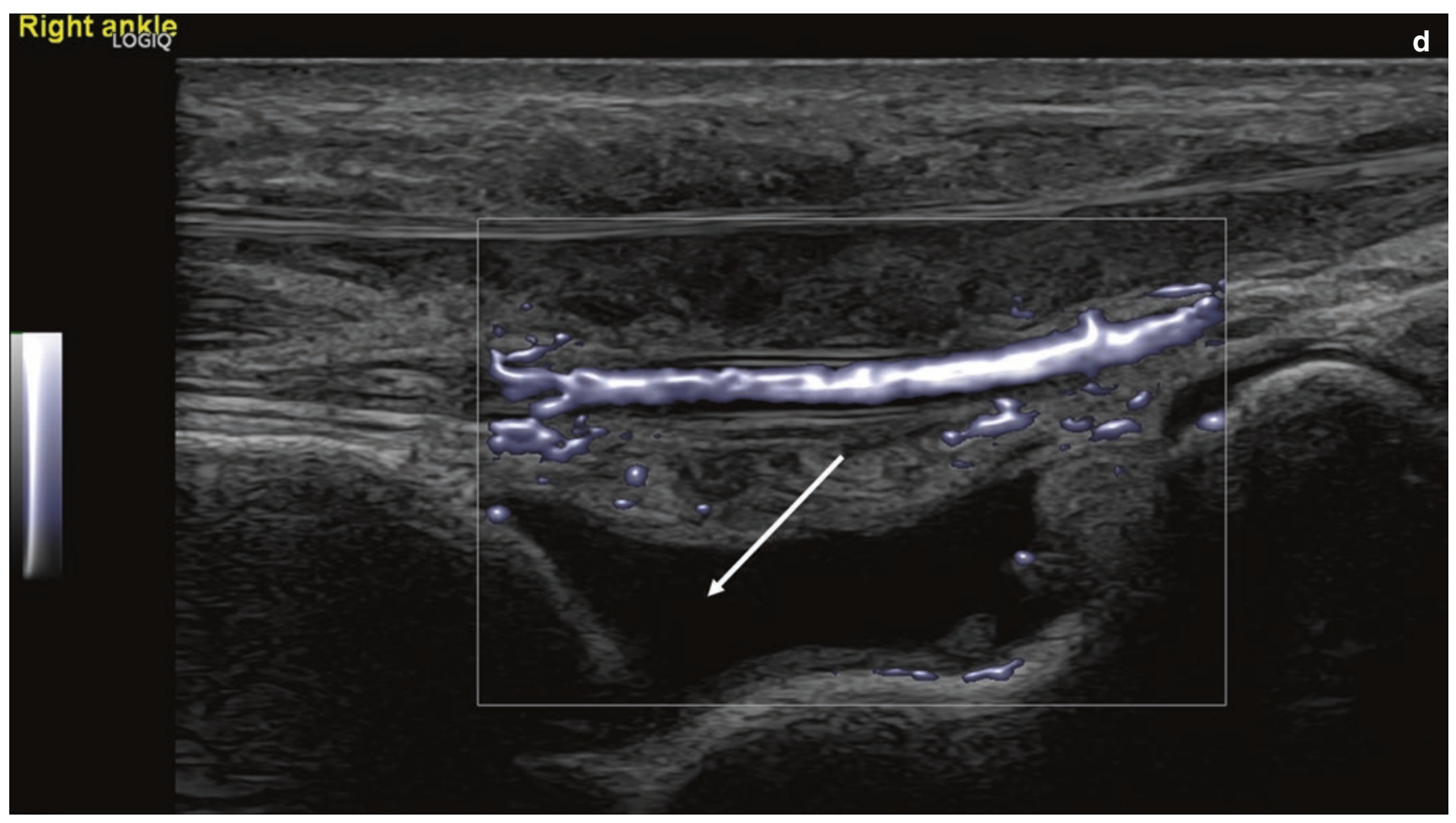

Fig. 16.11 (continued)

ation of the peroneal tendons. Injury in this region can also lead to pseudo-subluxation of the peroneal tendons when there is an abnormal movement of the peroneus brevis tendon against the peroneal longus. Both of these abnormalities can be a cause of clicking of the tendons in this region [33]. Dynamic assessment of tendon movement and retinaculum function is only available with diagnostic ultrasound. Intermittent or transient symptoms are often not identified using MRI or CT.

Ballet dancers suffer problems with the flexor hallucis longus tendon due to dancing on pointe over many years. This tendon is naturally larger than the other tendons in these dancers. Active tendinopathy with neovascularisation is easily demonstrated using diagnostic ultrasound.

\section{Key Points}

- Complete Achilles rupture is best assessed by ultrasound due to dynamic movement of the tendon showing the tendon ends moving in different directions. This technique has greater precision than MRI.

- Clicking of the peroneal tendons can either be due to pseudo subluxation or true subluxation which can be dynamically demonstrated using ultrasound.

- Ligamentous injury in the ankle is best seen by ultrasound due to the different obliquities of the ligaments; integrity of the ligament may be judged stressing the ligament while scanning.

\subsubsection{Foot}

The scanning technique is similar to that of the ankle using a large amount of coupling gel, and light touch around this area as pressure over the bones of the ankle can be very painful and you can compress fluid around joints and tendons.

The tibialis anterior tendon is affected in fell walkers. This is usually due to an insertional tendinosis.

The tibialis posterior tendon can rupture or develop tendinopathy. As this tendon forms part of the arch of the foot, these abnormalities can both cause a new flat foot deformity. The spring ligament can also be injured causing an acute flatfoot. These conditions are readily diagnosed using diagnostic ultrasound with high-resolution probes and good-quality Doppler imaging.

Ligamentous injury of the small ligaments of the foot can be identified using diagnostic ultrasound, especially if they are superficial. Injury to the talonavicular ligament can occur in isolation or in association with lateral ligamentous injury [34]. This destabilises the midfoot allowing movement across the talonavicular joint which is vital in the normal windlass mechanism of walking; this is the dynamic tightening of the arch of the foot by long and short stabilisers prior to pushing off from the ball of the foot. Deficiency in the strength of the arch prevents this movement and is associated with premature osteoarthritis of the midfoot.

Nerve damage can occur in athletes due to poor fitting shoes or the constant agitation of the deep peroneal nerve on 


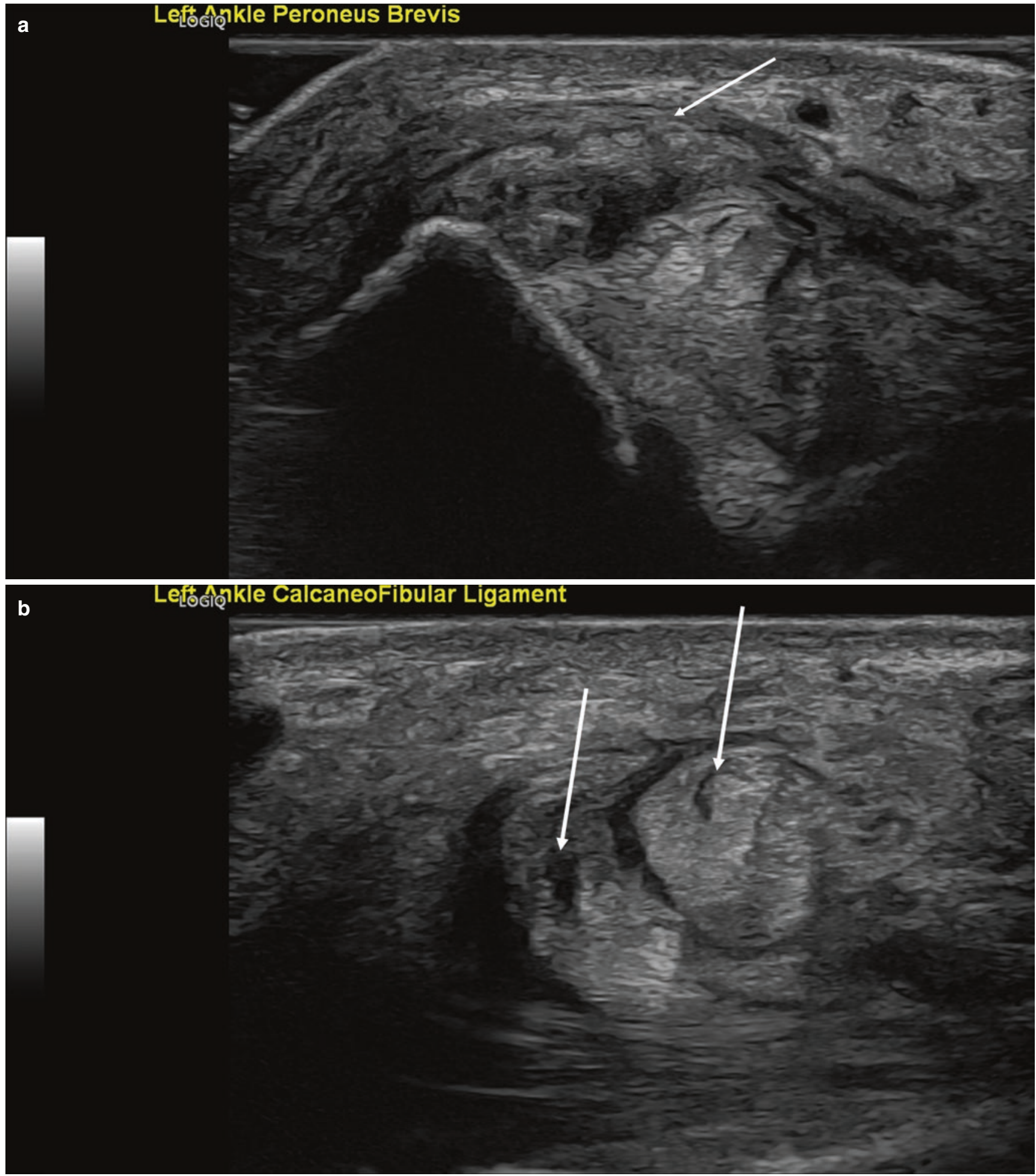

Fig. 16.12 An elite 55-year-old jockey. Peroneus longus and brevis tendinosis and superior peroneal retinacular injury. (a) Note the thickening of the superior peroneal retinaculum. (b) The peroneal tendons show central mucoid degeneration 
the dorsum of the foot of the ball in soccer players kicking a ball. This can easily be seen by ultrasound examination ideally with a high-resolution small footplate probe such as 18-24 MHz. Microvascular imaging allows study of the normal blood supply to small nerves, and comparison of both sides will determine whether flow is abnormally increased.

\section{Key Points}

- The cause of a sudden flat foot deformity can be tibialis posterior tendon rupture, tendinosis or spring ligament rupture. These can all be determined by ultrasound.

- Nerves can be clearly seen on ultrasound examination with high-resolution (18-24 MHz) probes.

\subsubsection{Muscle Injury}

Diagnostic ultrasound may be used to assess muscle tears $6 \mathrm{~h}$ after injury. Before this, acute haemorrhage is echogenic and blends with the fibro-fatty interfaces of the muscle and is therefore invisible. This makes the use of pitch side ultrasound inaccurate as significant muscle damage can be overlooked. Within a few hours, liquefying haematoma forms. This is low in echogenicity and is easy to see within the muscle. It forms in the gap of the muscle injury. Ultrasound can be used to dynamically assess the size of the tear by contracting the muscle passively or actively; the movement involved is minimal and should not be enough to cause any pain. MRI can be useful in the initial phase of an injury but will overestimate the extent of injury after $24 \mathrm{~h}$ due to distant spread of muscle oedema in association with the injury. MRI is rarely accurate in distinguishing between partial- and fullthickness rupture. In chronic injury muscle atrophy is seen as a change in size with fatty infiltration (increased echogenicity) and best determined by comparing sides. MRI provides similar information but sometimes only one limb is examined preventing comparison. In those with chronic injury the ultrasound practitioner should always compare sides looking for chronic muscle change.

The technique of muscle ultrasound examination requires a lower frequency probe such as $8-12 \mathrm{MHz}$ dependent on the depth and size of the muscle. It is best to use a fast sweeping motion over the muscle to detect the initial area of injury and then closing in on abnormal areas with slower movement to demonstrate more detail. Too much pressure can compress a liquefying haematoma making it more difficult to identify. Comparison with the opposite limb is essential to detect small areas of injury.

Diagnostic ultrasound can precisely identify scarring and myositis ossificans if the injuries are more established. Both these conditions are difficult to appreciate on MRI and are commonly overlooked. Scarring is of high echogenicity when established. Myositis ossificans is of high echogenicity and has acoustic shadowing behind it once it is established. The early calcification can be much easier to see using diagnostic ultrasound when compared to conventional radiography. Re-tearing can also be seen as low echogenicity and blurring of the normal muscle fibre pattern with vascularity in the region of a new tear [26].

Injuries may occur in any lower limb muscle group. The commonly seen injuries are of the hamstrings, quadriceps, adductors and calf muscles. Thigh muscle injury has been extensively researched in footballers. The presence of a musculotendinous injury or a large injury makes the time of returning to sport longer and the chance of a re-injury higher $[35,36]$.

Calf injuries commonly occur between the medial gastrocnemius and soleus muscles and are known as tennis leg. This can be mistaken for deep venous thrombosis or a ruptured popliteal cyst, but to the experienced ultrasound examiner, it is easy to distinguish between these disorders (Fig. 16.13).

\section{Key Points}

- Muscle injury may be invisible to ultrasound examination in the first $6 \mathrm{~h}$ after an injury as acute haemorrhage is echogenic and may mimic muscle.

- After $6 \mathrm{~h}$, ultrasound accurately detects the injury as haematoma starts to liquefy. At this stage MRI may exaggerate the nature of the injury because of adjacent muscle oedema.

\subsection{Guided Injections}

Ultrasound is becoming essential to the safe guidance of all interventions in both the upper and lower limb. This is beyond the remit of this article but is an extension of its use once you become proficient $[37,38]$. 

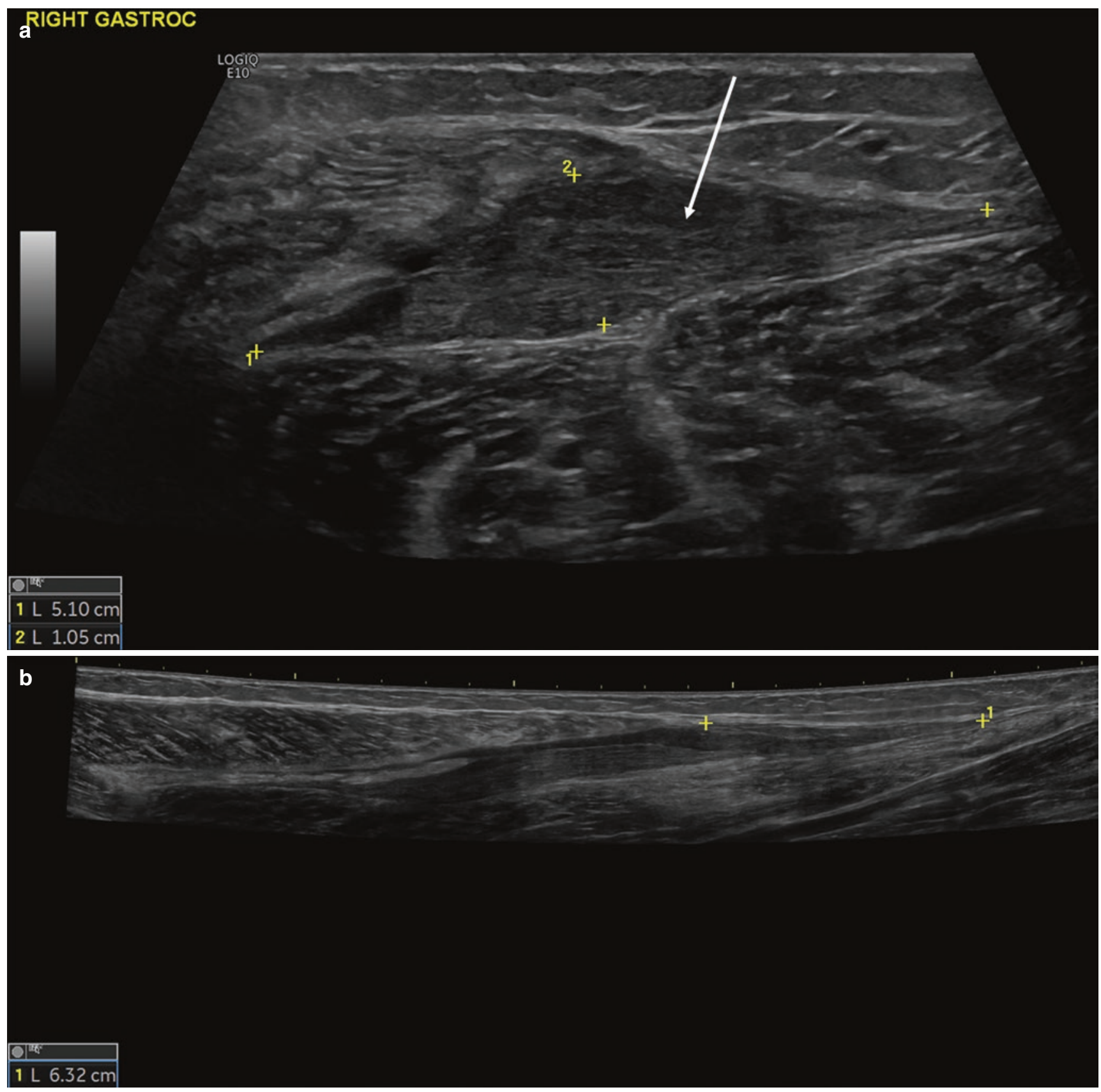

Fig. 16.13 A 50-year-old female skier. Injury in March 2020 just before lockdown for Covid 19. Stretching injury to the calf as she fell with ski moving forward. Imaged 5 months after injury as still symptomatic. (a) Poorly liquefied haematoma at site of injury between the gastrocnemius and soleus muscles. (b) Extended field of view ultrasound to show the amount of retraction of the medial gastrocnemius muscle with respect to the Achilles tendon 


\subsection{Concluding Remarks}

Ultrasound can play a significant role in the evaluation of sports injuries. The most common application is evaluation of tendon pathology, such as tendinosis and tendon tear. While any tendon about the extremities can be evaluated, the high-resolution capabilities of ultrasound are especially ideal in evaluation of the distal extremities. The dynamic capabilities of ultrasound are also important showing tendon retraction in the setting of a full-thickness tendon tear, tendon subluxation and muscle hernias. Muscle injuries may also be evaluated for tear and haematoma although sensitivity is lower acutely after an injury. Ligaments may be assessed with ultrasound where dynamic imaging can also be used to demonstrate joint space gapping as an indicator of ligament tear. Dynamic assessment is also important in the evaluation of groin hernias. Ultrasound may be used to guide various procedures, such as injections and aspirations, as they relate to sports injuries.

\section{Take Home Messages}

- Ultrasound is effective in the evaluation of tendon and ligament injuries.

- Ultrasound may be limited in the early evaluation of muscle injury.

- Dynamic imaging is important in evaluation of muscle and ligament tears, tendon subluxation as well as various hernias.

- Ultrasound may be used to guide percutaneous procedures.

\section{References}

1. Schaeffeler C, Mueller D, Kirchhoff C, Wolf P, Rummeny EJ, Woertler K. Tears at the rotator cuff footprint: prevalence and imaging characteristics in $305 \mathrm{MR}$ arthrograms of the shoulder. Eur Radiol. 2011;21(7):1477-84. Epub 2011/01/27. https://doi. org/10.1007/s00330-011-2066-x.

2. Jacobson JA. Shoulder US: anatomy, technique, and scanning pitfalls. Radiology. 2011;260(1):6-16. Epub 2011/06/24. https://doi. org/10.1148/radiol.11101082.

3. Galloway MT, Lalley AL, Shearn JT. The role of mechanical loading in tendon development, maintenance, injury, and repair. J Bone Joint Surg Am. 2013;95(17):1620-8. Epub 2013/09/06. https://doi. org/10.2106/JBJS.L.01004.

4. Buck FM, Grehn H, Hilbe M, Pfirrmann CW, Manzanell S, Hodler J. Magnetic resonance histologic correlation in rotator cuff tendons. J Magn Reson Imaging. 2010;32(1):165-72. Epub 2010/06/26. https://doi.org/10.1002/jmri.22222.

5. Kjellin I, Ho CP, Cervilla V, Haghighi P, Kerr R, Vangness CT, et al. Alterations in the supraspinatus tendon at MR imaging: correlation with histopathologic findings in cadavers. Radiology. 1991;181(3):837-41.
6. Jacobson JA, Lancaster S, Prasad A, van Holsbeeck MT, Craig JG, Kolowich P. Full-thickness and partial-thickness supraspinatus tendon tears: value of US signs in diagnosis. Radiology. 2004;230(1):234-42.

7. Wohlwend JR, van Holsbeeck M, Craig J, Shirazi K, Habra G, Jacobsen G, et al. The association between irregular greater tuberosities and rotator cuff tears: a sonographic study. AJR Am J Roentgenol. 1998;171(1):229-33.

8. Araki D, Miller RM, Fujimaki Y, Hoshino Y, Musahl V, Debski RE. Effect of tear location on propagation of isolated supraspinatus tendon tears during increasing levels of cyclic loading. J Bone Joint Surg Am. 2015;97(4):273-8. Epub 2015/02/20. https://doi. org/10.2106/JBJS.N.00062.

9. Park JS, Park HJ, Kim SH, Oh JH. Prognostic factors affecting rotator cuff healing after arthroscopic repair in small to medium-sized tears. Am J Sports Med. 2015;43(10):2386-92. Epub 2015/08/20. https://doi.org/10.1177/0363546515594449.

10. Skendzel JG, Jacobson JA, Carpenter JE, Miller BS. Long head of biceps brachii tendon evaluation: accuracy of preoperative ultrasound. AJR Am J Roentgenol. 2011;197(4):942-8. Epub 2011/09/24. https://doi.org/10.2214/AJR.10.5012.

11. Moser TP, Cardinal E, Bureau NJ, Guillin R, Lanneville P, Grabs $D$. The aponeurotic expansion of the supraspinatus tendon: anatomy and prevalence in a series of 150 shoulder MRIs. Skelet Radiol. 2015;44(2):223-31. Epub 2014/09/03. https://doi.org/10.1007/ s00256-014-1993-4.

12. Hashiuchi T, Sakurai G, Morimoto M, Komei T, Takakura Y, Tanaka Y. Accuracy of the biceps tendon sheath injection: ultrasoundguided or unguided injection? A randomized controlled trial. J Shoulder Elb Surg. 2011;20(7):1069-73. Epub 2011/07/26. https:// doi.org/10.1016/j.jse.2011.04.004.

13. van Holsbeeck M, Strouse PJ. Sonography of the shoulder: evaluation of the subacromial-subdeltoid bursa. AJR Am J Roentgenol. 1993;160(3):561-4. Epub 1993/03/01. https://doi.org/10.2214/ ajr.160.3.8430553.

14. Daghir AA, Sookur PA, Shah S, Watson M. Dynamic ultrasound of the subacromial-subdeltoid bursa in patients with shoulder impingement: a comparison with normal volunteers. Skelet Radiol. 2012;41(9):1047-53. Epub 2011/10/15. https://doi.org/10.1007/ s00256-011-1295-z.

15. Lobo Lda G, Fessell DP, Miller BS, Kelly A, Lee JY, Brandon C, et al. The role of sonography in differentiating full versus partial distal biceps tendon tears: correlation with surgical findings. AJR Am J Roentgenol. 2013;200(1):158-62. Epub 2012/12/21. https:// doi.org/10.2214/AJR.11.7302.

16. Smith J, Finnoff JT, O’Driscoll SW, Lai JK. Sonographic evaluation of the distal biceps tendon using a medial approach: the pronator window. J Ultrasound Med. 2010;29(5):861-5. Epub 2010/04/30

17. Kalume Brigido M, De Maeseneer M, Jacobson JA, Jamadar DA, Morag Y, Marcelis S. Improved visualization of the radial insertion of the biceps tendon at ultrasound with a lateral approach. Eur Radiol. 2009;19(7):1817-21. Epub 2009/02/14. https://doi. org/10.1007/s00330-009-1321-x.

18. Downey R, Jacobson JA, Fessell DP, Tran N, Morag Y, Kim SM. Sonography of partial-thickness tears of the distal triceps brachii tendon. J Ultrasound Med. 2011;30(10):1351-6. Epub 2011/10/05

19. Potter HG, Hannafin JA, Morwessel RM, DiCarlo EF, O’Brien SJ, Altchek DW. Lateral epicondylitis: correlation of MR imaging, surgical, and histopathologic findings. Radiology. 1995;196(1): 43-6.

20. Roedl JB, Gonzalez FM, Zoga AC, Morrison WB, Nevalainen MT, Ciccotti MG, et al. Potential utility of a combined approach with US and MR arthrography to image medial elbow pain in baseball players. Radiology. 2016;279(3):827-37. Epub 2016/05/18. https:// doi.org/10.1148/radiol.2015151256. 
21. De Maeseneer M, Marcelis S, Jager T, Girard C, Gest T, Jamadar D. Spectrum of normal and pathologic findings in the region of the first extensor compartment of the wrist: sonographic findings and correlations with dissections. J Ultrasound Med. 2009;28(6):77986. Epub 2009/05/28

22. Lopez-Ben R, Lee DH, Nicolodi DJ. Boxer knuckle (injury of the extensor hood with extensor tendon subluxation): diagnosis with dynamic US - report of three cases. Radiology. 2003;228(3):642-6.

23. Klauser A, Frauscher F, Bodner G, Halpern EJ, Schocke MF, Springer P, et al. Finger pulley injuries in extreme rock climbers: depiction with dynamic US. Radiology. 2002;222(3):755-61.

24. Melville D, Jacobson JA, Haase S, Brandon C, Brigido MK, Fessell D. Ultrasound of displaced ulnar collateral ligament tears of the thumb: the Stener lesion revisited. Skelet Radiol. 2013;42(5):66773. Epub 2012/09/25. https://doi.org/10.1007/s00256-012-1519-X.

25. Ebrahim FS, De Maeseneer M, Jager T, Marcelis S, Jamadar DA, Jacobson JA. US diagnosis of UCL tears of the thumb and Stener lesions: technique, pattern-based approach, and differential diagnosis. Radiographics. 2006;26(4):1007-20.

26. Allen GM. The use of ultrasound in athletes. Eur J Radiol. 2018;109:136-41. https://doi.org/10.1016/j.ejrad.2018.10.028.

27. Brandon CJ, Jacobson JA, Fessell D, Dong Q, Morag Y, Girish G, et al. Groin pain beyond the hip: how anatomy predisposes to injury as visualized by musculoskeletal ultrasound and MRI. AJR Am J Roentgenol. 2011;197(5):1190. https://doi.org/10.2214/AJR.10.4890.

28. Jacobson J, Khoury V, Brandon CJ. Ultrasound of the groin: techniques, pathology, and pitfalls. Am J Roentgenol. 2015;205(3):51323. https://doi.org/10.2214/AJR.15.14523.

29. Vasileff WK, Nekhline M, Kolowich PA, Talpos GB, Eyler WR, van Holsbeeck M. Inguinal hernia in athletes: role of dynamic ultrasound. Sports Health. 2017;9(5):414-21. Epub 2017/07/22. https:// doi.org/10.1177/1941738117717009.

30. Allen GM. Tendon and ligamentous trauma. In: Vanhoenacker FM, Maas, M., Gielen, J. L., editor. Imaging of orthopaedic sports injuries: Springer, New York; 2007. p. 61-72.
31. Rossi F, Dragoni S. Acute avulsion fractures of the pelvis in adolescent competitive athletes: prevalence, location and sports distribution of 203 cases collected. Skelet Radiol. 2001;30(3):127-31. Epub 2001/05/19. https://doi.org/10.1007/s002560000319.

32. Allen GM, Wilson DJ, Bullock SA, Watson M. Extremity CT and ultrasound in the assessment of ankle injuries: occult fractures and ligament injuries. Br J Radiol. 2020;93(1105):20180989. https:// doi.org/10.1259/bjr.20180989.

33. Bianchi S, Becciolini M. Ultrasound features of ankle retinacula: normal appearance and pathologic findings. J Ultrasound Med. 2019;38(12):3321-34. https://doi.org/10.1002/jum.15026.

34. De Dea M, Loizou C, Allen G, Wilson D, Athanasou N, Uchihara Y, et al. Talonavicular ligament: prevalence of injury in ankle sprains, histological analysis and hypothesis of its biomechanical function. Br J Radiol. 2017;90(1071):20160816. https://doi.org/10.1259/ bjr.20160816.

35. Ekstrand J, Askling C, Magnusson H, Mithoefer K. Return to play after thigh muscle injury in elite football players: implementation and validation of the Munich muscle injury classification. Br J Sports Med. 2013;47(12):769-74. https://doi.org/10.1136/ bjsports-2012-092092.

36. Pollock N, Patel A, Chakraverty J, Suokas A, James SL, Chakraverty $\mathrm{R}$. Time to return to full training is delayed and recurrence rate is higher in intratendinous ('c') acute hamstring injury in elite track and field athletes: clinical application of the British Athletics Muscle Injury Classification. Br J Sports Med. 2016;50(5):305-10. Epub 2016/02/19. https://doi.org/10.1136/bjsports-2015-094657.

37. Lee JC, Ahmed N, Allen GM. Image guided injection therapies in athletes - do they work and what should we be using? Eur J Radiol. 2019;110:193-202. https://doi.org/10.1016/j.ejrad.2018.12.001.

38. Allen GM, Wilson DJ. Ultrasound guided musculoskeletal injections. Amsterdam: Elsevier; 2018.

Open Access This chapter is licensed under the terms of the Creative Commons Attribution 4.0 International License (http://creativecommons. org/licenses/by/4.0/), which permits use, sharing, adaptation, distribution and reproduction in any medium or format, as long as you give appropriate credit to the original author(s) and the source, provide a link to the Creative Commons license and indicate if changes were made.

The images or other third party material in this chapter are included in the chapter's Creative Commons license, unless indicated otherwise in a credit line to the material. If material is not included in the chapter's Creative Commons license and your intended use is not permitted by statutory regulation or exceeds the permitted use, you will need to obtain permission directly from the copyright holder. 